\title{
High-performance organic thin-film transistor by using LaNbO as gate dielectric
}

\author{
C. Y. Han, ${ }^{1}$ J. Q. Song, ${ }^{1}$ W. M. Tang, ${ }^{2}$ C. H. Leung, ${ }^{1}$ and P. T. Lai ${ }^{1, a}$ ) \\ ${ }^{1}$ Department of Electrical and Electronic Engineering, The University of Hong Kong, Pokfulam Road, \\ Hong Kong \\ ${ }^{2}$ Department of Applied Physics, The Hong Kong Polytechnic University, Hung Hom, Hong Kong
}

(Received 21 March 2015; accepted 9 July 2015; published online 20 July 2015)

\begin{abstract}
Pentacene organic thin-film transistors (OTFTs) using $\mathrm{La}_{\mathrm{x}} \mathrm{Nb}_{(1-\mathrm{x})} \mathrm{O}_{\mathrm{y}}$ as gate dielectric with different La contents $(\mathrm{x}=0.347,0.648)$ have been fabricated and compared with those using $\mathrm{Nb}$ oxide or La oxide. The OTFT with $\mathrm{La}_{0.648} \mathrm{Nb}_{0.352} \mathrm{O}_{\mathrm{y}}$ as gate dielectric can achieve a high carrier mobility of $1.14 \mathrm{~cm}^{2} \mathrm{~V}^{-1} \mathrm{~s}^{-1}$ (about 1000 times and 2 times those of the devices using $\mathrm{Nb}$ oxide and La oxide, respectively), and has negligible hysteresis of $-0.130 \mathrm{~V}$, small sub-threshold swing of $0.280 \mathrm{~V} /$ dec, and low threshold voltage of $-1.35 \mathrm{~V}$. AFM and XPS reveal that La can suppress the formation of oxygen vacancies in $\mathrm{Nb}$ oxide while $\mathrm{Nb}$ can alleviate the hygroscopicity of La oxide, which results in a more passivated and smoother dielectric surface, leading to larger pentacene grains grown and thus higher carrier mobility. The OTFT with $\mathrm{Nb}$ oxide has an anticlockwise hysteresis but the device with La oxide shows an opposite direction. This can be explained in terms of donorlike traps due to oxygen vacancies and acceptor-like traps originated from hydroxyl ions formed after $\mathrm{La}_{2} \mathrm{O}_{3}$ absorbing water moisture. (C) 2015 AIP Publishing LLC.
\end{abstract}

[http://dx.doi.org/10.1063/1.4927098]

Pentacene organic thin-film transistors (OTFTs) have been intensively studied in the past three decades due to their potential applications in radio-frequency identification tags, sensors, and large-area flexible displays. Although some OTFTs have shown high carrier mobility comparable to that of amorphous silicon devices, ${ }^{1-3}$ the operating voltage of the OTFTs still needs to be reduced as many electronic products work with battery at just a few volts. OTFTs fabricated with traditional $\mathrm{SiO}_{2}$, PMMA, or polyvidone (PVP) as gate dielectric require a high operating voltage due to large threshold voltage $(>5 \mathrm{~V}) .^{4-6}$ There are several ways to reduce the threshold voltage: (1) Use cross-linking agents to modify the low- $\kappa$ polymer gate dielectrics; ${ }^{7,8}$ (2) use hybrid organicinorganic dielectrics with smaller thickness; $;^{9,10}$ (3) use high- $\kappa$ materials as gate dielectric. Various high- $\kappa$ materials have been employed as the gate dielectric of pentacene OTFTs, and their carrier mobility varies from $2 \times 10^{-2}$ to $1.4 \mathrm{~cm}^{2} \mathrm{~V}^{-1} \mathrm{~s}^{-1}$ with low threshold voltage. ${ }^{11-13}$ The performance of the OTFT highly depends on the quality of its high- $\kappa$ gate dielectric, such as surface roughness and trap density. Recently, the addition of La has been reported to suppress the oxygen vacancies in Hfbased high- $\kappa$ materials, ${ }^{14,15}$ and $\mathrm{HfLaO}$ was used as gate dielectric for high-performance pentacene OTFTs, showing high carrier mobility, small threshold voltage, low hysteresis, and small sub-threshold swing (SS). ${ }^{16,17}$

$\mathrm{Nb}_{2} \mathrm{O}_{5}$ has high $\kappa$ value $(\sim 29)$, but it has small band gap $(\sim 4.4 \mathrm{eV})$ and suffers from a high concentration of oxygen vacancies, ${ }^{18}$ whose gap states lead to charge trapping. On the other hand, $\mathrm{La}_{2} \mathrm{O}_{3}$ has larger band gap $(\sim 6 \mathrm{eV})$, but it is very hygroscopic and unstable in air, easily forming hydroxide. ${ }^{19}$ In this work, $\mathrm{La}_{\mathrm{x}} \mathrm{Nb}_{(1-\mathrm{x})} \mathrm{O}_{\mathrm{y}}$ films with different $\mathrm{La}$ contents

\footnotetext{
a) Author to whom correspondence should be addressed. Electronic mail: laip@eee.hku.hk
}

are prepared by $\mathrm{RF}$ sputtering and proposed as the gate dielectric of pentacene OTFT in an attempt to combine the advantages of $\mathrm{La}_{2} \mathrm{O}_{3}$ and $\mathrm{Nb}_{2} \mathrm{O}_{5}$ while suppressing their undesirable properties. By using $\mathrm{La}_{\mathrm{x}} \mathrm{Nb}_{(1-\mathrm{x})} \mathrm{O}_{\mathrm{y}}$ with an appropriate La content $(64.8 \% \mathrm{La})$ as gate dielectric, highperformance OTFT with high carrier mobility and low threshold voltage can be obtained.

Initially, the standard RCA method was employed to clean silicon wafers (n-type, $\langle 100\rangle$, resistivity of $0.5 \sim 1.0$ $\Omega \cdot \mathrm{cm})$. After removing the native oxide by dipping the wafers in $2 \%$ hydrofluoric acid, $\mathrm{La}_{\mathrm{x}} \mathrm{Nb}_{(1-\mathrm{x})} \mathrm{O}_{\mathrm{y}}$ (with $\mathrm{x}=0$, $0.347,0.648$ and 1) films were deposited on the wafers as gate dielectric by sputtering in an $\mathrm{Ar} / \mathrm{O}_{2}(24: 6 \mathrm{sccm})$ ambient with a radio-frequency sputterer (Denton Vacuum LLC Discovery 635) using $\mathrm{Nb}$ and $\mathrm{La}_{2} \mathrm{O}_{3}$ targets. After that, the samples were annealed in $\mathrm{N}_{2}$ at $400{ }^{\circ} \mathrm{C}$ for $20 \mathrm{~min}$, with a flow rate of $1000 \mathrm{sccm}$. Next, an evaporator (Edwards Auto 306) was used to deposit 30-nm pentacene ( $>99 \%$, purchased from Lumtech) on the dielectrics in high vacuum $\left(3.8 \times 10^{-6}\right.$ torr $)$ at a deposition rate of $1.2 \mathrm{~nm} / \mathrm{min}$. Finally, the drain and source electrodes of the OTFTs were evaporated through a shadow mask with a channel of $200 \mu \mathrm{m}$ in width and $30 \mu \mathrm{m}$ in length.

The electrical characteristics of the OTFTs were characterized by HP 4145B semiconductor parameter analyzer. Al/ high- $\kappa$ dielectric/heavily doped Si MOS structure was also fabricated by lithography and measured by HP 4284A precision LCR meter to extract the capacitance per unit area $\left(\mathrm{C}_{\mathrm{ox}}\right)$. All the measurements were conducted at room temperature, in air, and under shielded environment. The thickness of the dielectric films was measured by a Wvase 32 ellipsometer. A Veeco multi-mode scanning probe microscope was employed to record the surface morphologies of the dielectrics and pentacene films, and X-ray photoelectron spectroscopy 

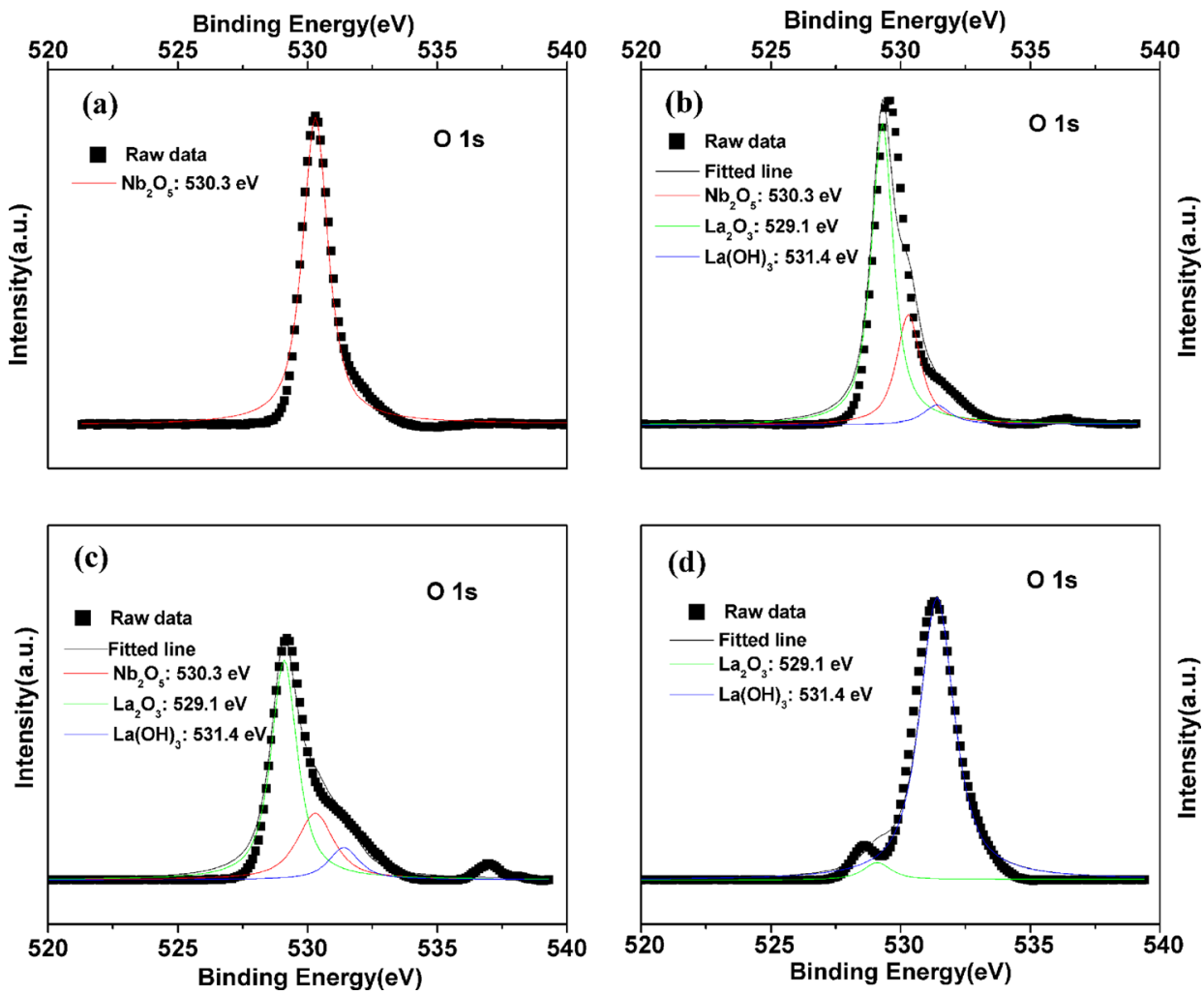

FIG. 1. XPS spectrum of $\mathrm{O} 1 \mathrm{~s}$ for $\mathrm{La}_{\mathrm{x}} \mathrm{Nb}_{(1-\mathrm{x})} \mathrm{O}_{\mathrm{y}}$ with $\mathrm{x}=0$ (a), 0.347 (b), 0.648 (c), and $1(\mathrm{~d})$.
(XPS) was employed to analyze the physical characteristics of the high- $\kappa$ dielectric films. The binding energies were corrected based on $\mathrm{C} 1 \mathrm{~s}$ peak at $284.5 \mathrm{eV}$.

According to XPS results, the atomic ratio of $\mathrm{La} /$ $(\mathrm{Nb}+\mathrm{La})$ is $0 \%, 34.7 \%, 64.8 \%$, and $100 \%$ for the 4 samples, denoted as A, B, C, and D, respectively. Fig. 1 shows the XPS spectrum of O $1 s$ core levels for the dielectric films. It is clear that when the La content increases, more La-OH bonds are formed in the $\mathrm{La}_{\mathrm{x}} \mathrm{Nb}_{(1-\mathrm{x})} \mathrm{O}_{\mathrm{y}}$ film due to the hygroscopicity of the La oxide. Sample D (with $\mathrm{x}=1$ ) becomes almost $\mathrm{La}(\mathrm{OH})_{3}$ due to the absorption of the moisture in the air.

Fig. 2 shows the XPS spectra of $\mathrm{Nb} 3 d$ and La $3 d$. As shown in Fig. 2(a), the binding energy of $\mathrm{Nb} 3 d$ shifts to lower value with the increase of the La content, which should be caused by the La incorporation suppressing the oxygen vacancy in the $\mathrm{Nb}$ oxide. It is widely accepted that the oxygen vacancy is positively charged and generates an electric field, ${ }^{20-22}$ thus leading to binding-energy shift. ${ }^{23}$ The binding energy increases when an atom is placed near a positive charge. ${ }^{23}$ Hence, reducing the oxygen vacancies in the $\mathrm{Nb}$ oxide and thus the positive charges around the $\mathrm{Nb}$ atoms by the addition of La can result in a shift of $\mathrm{Nb} 3 d$ peak toward lower binding energy by $1.1 \mathrm{eV}$ when La content reaches $64.8 \%$ in sample $\mathrm{C}$. On the other hand, incorporating $\mathrm{Nb}$ in La oxide can generate more positive oxygen vacancies, resulting in higher binding energy for La $3 d$. However, Fig. 2(b) shows that the binding energy of La first decreases but then increases with increasing $\mathrm{Nb}$ content. $\mathrm{La}-\mathrm{OH}$ bond has higher binding energy than La-O bond. The La $3 d$ peak first shifts to lower binding energy because $\mathrm{Nb}$ incorporation enhances the moisture resistance of La oxide, thus reducing the $\mathrm{La}-\mathrm{OH}$ bond in the oxide. Further increasing the $\mathrm{Nb}$ content can generate more oxygen vacancies, leading to a shift of the binding energy to a higher value.
The surface roughness of the dielectric is an important parameter in deciding the pentacene growth and thus device performance. Reducing the surface roughness (thus nucleation sites for pentacene growth) can cause increases in

Binding Energy (eV)

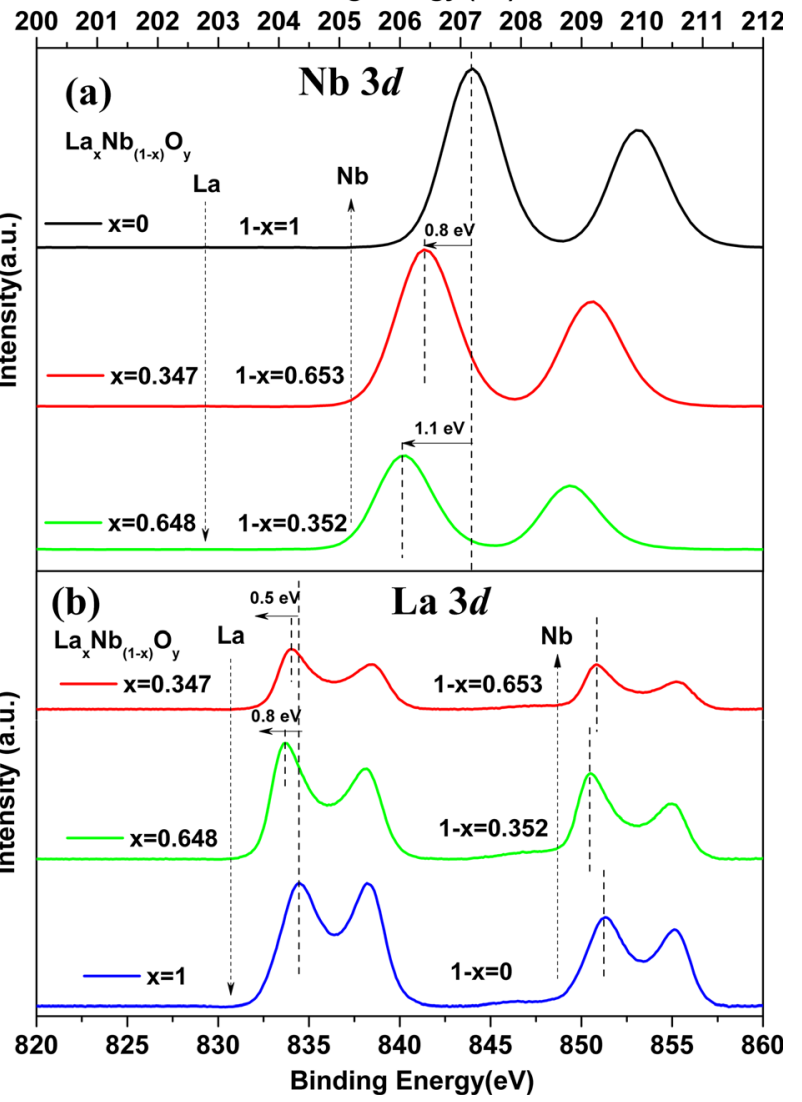

FIG. 2. XPS spectra of $\mathrm{Nb} 3 d$ (a) and La $3 d$ (b). 

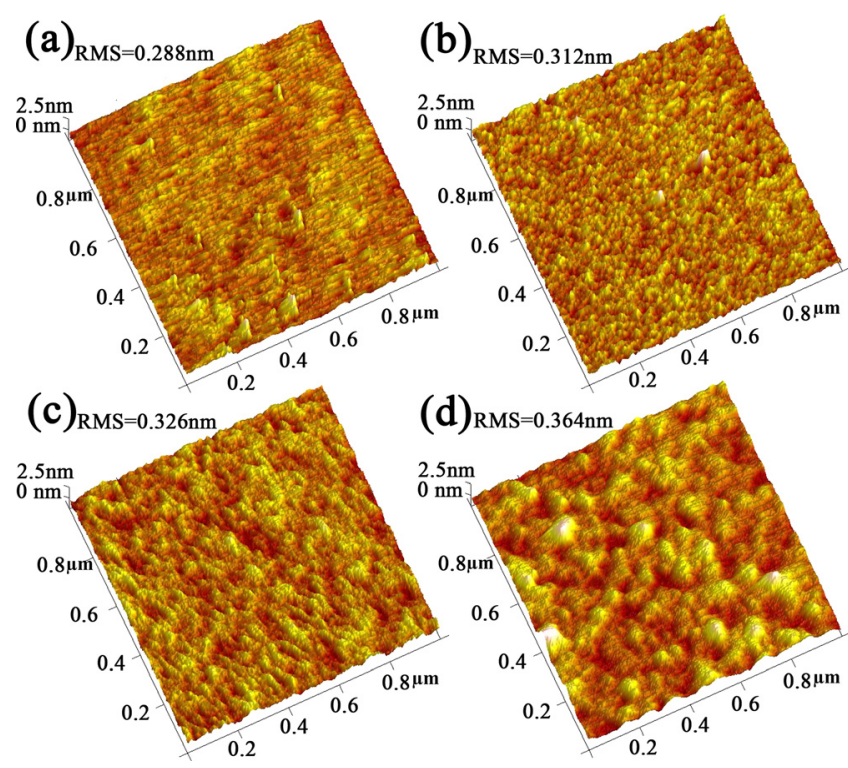

FIG. 3. AFM image of the gate dielectric films: (a) for sample A with RMS $=0.288 \mathrm{~nm}$; (b) for sample B with RMS $=0.312 \mathrm{~nm}$; (c) for sample C with RMS $=0.326 \mathrm{~nm}$, and (d) for sample D with RMS $=0.364 \mathrm{~nm}$.

pentacene grain size and carrier mobility. ${ }^{24,25}$ La oxide is unstable in the air, and its surface roughness is increased after absorbing the moisture in the air. As depicted in Fig. 3, incorporation of $\mathrm{Nb}$ in $\mathrm{La}_{2} \mathrm{O}_{3}$ reduces the surface roughness of the gate dielectric from $0.364 \mathrm{~nm}$ to $0.288 \mathrm{~nm}$ because the addition of $\mathrm{Nb}$ can alleviate the hygroscopicity of La oxide.

The surface energy $\left(\gamma_{S}\right)$ of the samples is calculated by measuring the contact angles $(\theta)$ of three liquids (water, diiodomethane and glycerol) in static mode. The relation between the surface energy and contact angle is expressed by ${ }^{26}$

TABLE I. Main parameters of OTFTs with different La concentrations extracted from the off-to-on sweep of transfer characteristics and properties of gate dielectrics. With 11 devices measured for each sample, the average values of the parameters are listed together with the highest carrier mobility and standard deviation (SD).

\begin{tabular}{|c|c|c|c|c|}
\hline Sample No. & A & B & $\mathrm{C}$ & $\mathrm{D}$ \\
\hline $\mathrm{La} /(\mathrm{Nb}+\mathrm{La})$ & 0 & 0.347 & 0.648 & 1 \\
\hline$\mu\left(\mathrm{cm}^{2} \mathrm{~V}^{-1} \mathrm{~s}^{-1}\right)$ & 0.001 & 0.543 & 1.14 & 0.519 \\
\hline (SD) & $\left(5.3 \times 10^{-4}\right)$ & $(0.059)$ & $(0.096)$ & $(0.098)$ \\
\hline Highest & 0.002 & 0.612 & 1.30 & 0.690 \\
\hline $\mathrm{V}_{\mathrm{T}}(\mathrm{V})$ & 3.28 & -0.85 & -1.35 & -2.25 \\
\hline (SD) & $(0.495)$ & $(0.214)$ & $(0.189)$ & $(0.289)$ \\
\hline$\Delta \mathrm{V}_{\mathrm{T}}(\mathrm{V})$ & 1.52 & 1.09 & -0.13 & -0.34 \\
\hline $\mathrm{SS}(\mathrm{V} / \mathrm{dec})$ & 3.41 & 0.279 & 0.208 & 0.346 \\
\hline $\mathrm{I}_{\mathrm{on}} / \mathrm{I}_{\mathrm{off}}$ & 753 & $4.78 \times 10^{4}$ & $2.90 \times 10^{5}$ & $2.93 \times 10^{4}$ \\
\hline $\mathrm{I}_{\mathrm{on}}(\mu \mathrm{A}) @ \mathrm{~V}_{\mathrm{D}}=\mathrm{V}_{\mathrm{G}}=-5 \mathrm{~V}$ & 0.153 & 8.15 & 10.46 & 4.45 \\
\hline $\mathrm{C}_{\mathrm{ox}}\left(\mu \mathrm{F} \cdot \mathrm{cm}^{2}\right)$ & 1.10 & 0.267 & 0.222 & 0.220 \\
\hline$\mu \mathrm{C}_{\mathrm{ox}}\left(\mu \mathrm{F} \cdot \mathrm{V}^{-1} \mathrm{~S}^{-1}\right)$ & 0.00122 & 0.145 & 0.253 & 0.114 \\
\hline $\mathrm{t}_{\mathrm{ox}}(\mathrm{nm})$ & 32.2 & 38.3 & 42.9 & 32.3 \\
\hline Dielectric constant & 39.7 & 11.6 & 10.7 & 8.0 \\
\hline$N_{\mathrm{t}}\left(\mathrm{cm}^{-2} \mathrm{eV}^{-1}\right)$ & \multicolumn{4}{|c|}{$3.87 \times 10^{14} 6.15 \times 10^{12} 3.46 \times 10^{12} 6.61 \times 10^{12}$} \\
\hline$\gamma^{\mathrm{p}}\left(\mathrm{mJm}^{-2}\right)$ & 14.7 & 25.4 & 26.8 & 29.5 \\
\hline$\gamma^{\mathrm{d}}\left(\mathrm{mJm} \mathrm{m}^{-2}\right)$ & 39.9 & 38.5 & 37.2 & 35.3 \\
\hline$\gamma_{\mathrm{S}}\left(\mathrm{mJm}^{-2}\right)$ & 54.6 & 63.9 & 64.0 & 64.8 \\
\hline
\end{tabular}

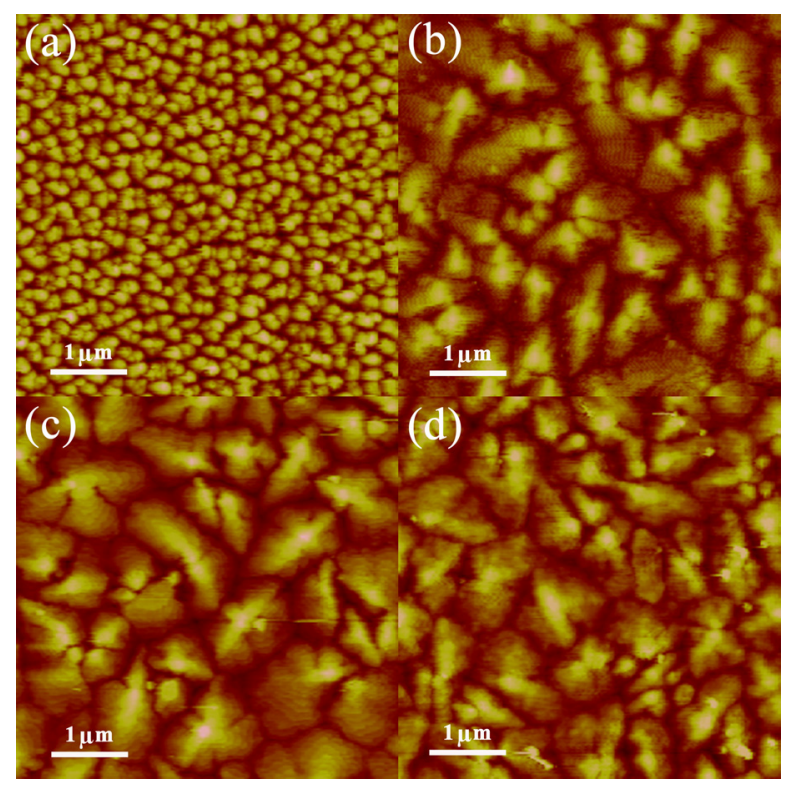

FIG. 4. AFM image $\left(5 \times 5 \mu \mathrm{m}^{2}\right)$ of pentacene film $(30 \mathrm{~nm})$ on $\mathrm{La}_{\mathrm{x}} \mathrm{Nb}_{(1-\mathrm{x})} \mathrm{O}_{\mathrm{y}}$ with $\mathrm{x}=$ : (a) 0 for sample A, (b) 0.347 for sample $\mathrm{B}$, (c) 0.648 for sample C, and (d) 1 for sample D.

$$
1+\cos (\theta)=\frac{2\left(\gamma^{d}\right)^{1 / 2}\left(\gamma_{L}^{d}\right)^{1 / 2}}{\gamma_{L}}+\frac{2\left(\gamma^{p}\right)^{1 / 2}\left(\gamma_{L}^{p}\right)^{1 / 2}}{\gamma_{L}},
$$

where $\gamma^{d}$ and $\gamma^{p}$ are the dispersion and polar components of the surface energy, respectively, and the total surface energy $\gamma_{S}$ is calculated by summing the two components. The surface energy $\left(\gamma_{L}\right)$, dispersion component $\left(\gamma_{L}^{d}\right)$ and polar component $\left(\gamma_{L}^{p}\right)$ used to solve Eq. (1) for $\gamma^{d}$ and $\gamma^{p}$ are, respectively, $77.2,22.0$, and $50.2 \mathrm{mJm}^{-2}$ for water, 64,34 , and $30 \mathrm{mJm}^{-2}$ for glycerol, and $50.8,48.5$, and $2.3 \mathrm{mJm}^{-2}$ for diiodomethane. As shown in Table I, for increasing La content, the total surface energy and the polar component increase, but the dispersion component decreases.

Fig. 4 shows the AFM image of 30-nm pentacene film deposited on different dielectric films. Higher surface energy was reported to cause larger pentacene grains. ${ }^{27-29}$ So, by comparing samples $\mathrm{B}, \mathrm{C}$, and D with sample A, it is highly possible that their higher surface energies (see Table I) cause the larger grains. Sample $\mathrm{C}$ has nearly the same surface energy as sample B but lower surface energy than sample D. However, sample $C$ has the largest grains among the samples. This indicates that surface roughness and oxygen vacancies (both can act as nucleation centers) can also impact the surface morphology of the pentacene film. The pentacene grains on the La-doped $\mathrm{Nb}$ oxide or La oxide (see Figs. 4(b)-4(d)) are much larger than those on the $\mathrm{Nb}$ oxide (see Fig. 4(a)). Although the $\mathrm{Nb}$ oxide has the smoothest surface among the samples, the pentacene grain size on $\mathrm{Nb}$ oxide is the smallest, indicating that the oxygen vacancies at the dielectric surface can act as nucleation sites in the process of pentancene growth, and smaller grains are formed on the surface with more nucleation sites. ${ }^{30-33}$ On the other hand, larger pentacene grains can be formed on the La-doped $\mathrm{Nb}$ oxide and $\mathrm{La}$ oxide films with fewer nucleation sites. Moreover, by comparing sample A with samples B and C, it can be concluded that the oxygen vacancies at the dielectric 
surface play a more important role than the surface roughness of the gate dielectric in the nucleation process of pentacene growth.

Assuming the densities of deep bulk trap and deep interface trap are independent of trap energy, ${ }^{34}$ the trap density at the interface can be extracted from $S S$ as

$$
N_{t}=\frac{C_{o x}}{e}\left(\frac{e \cdot S S}{k T \ln 10}-1\right)
$$

where $N_{t}$ is the density of deep bulk trap and interface trap per unit area and unit energy, $k$ the Boltzmann's constant, $e$ the electron charge, and $T$ the temperature in Kelvin. Therefore, the trap density at the interface can be calculated from the measured $S S$ value.

The transfer and hysteresis characteristics of the OTFTs are shown in Fig. 5. The off-on (forward) sweep was measured by decreasing the gate voltage from $3 \mathrm{~V}$ to $-5 \mathrm{~V}$, while the on-off (reverse) sweep was done by increasing the gate voltage from $-5 \mathrm{~V}$ to $3 \mathrm{~V}$. There was negligible pause time between the two sweeps. In Table I, the key parameters of the OTFTs are extracted from the off-to-on sweep of transfer characteristics and averaged over 11 devices. $\Delta \mathrm{V}_{\mathrm{T}}$ is defined as $\mathrm{V}_{\mathrm{T}}$ of off-to-on (forward) sweep minus $\mathrm{V}_{\mathrm{T}}$ of on-to-off (reverse) sweep as shown in Fig. 5(b). The OTFT with $\mathrm{La}_{0.648} \mathrm{Nb}_{0.352} \mathrm{O}_{\mathrm{y}}$ exhibits the highest carrier mobility of $1.14 \mathrm{~cm}^{-1} \mathrm{~V}^{-1} \mathrm{~s}^{-1}$, which is about 1000 times and 2 times higher than those of the devices using $\mathrm{Nb}$ oxide and $\mathrm{La}$ oxide, respectively. The highest carrier mobility of sample $\mathrm{C}$ (La 64.8\%) should be attributed to the largest pentacene grains (see Fig. 4) resulted from the best passivation of oxygen vacancy in the dielectric (smallest $S S$ or $\Delta \mathrm{V}_{\mathrm{T}}$ in Table I) by La incorporation and smooth dielectric surface (see Fig. 3(c)). With increasing Nb content, the carrier mobility firstly increases due to the smoother dielectric surface by $\mathrm{Nb}$ incorporation, but then decreases as more oxygen vacancies are generated by $\mathrm{Nb}$ incorporation, leading to smaller pentacene grains and more carrier scatterings at the grain boundaries.

Hysteresis effects are often observed in OTFTs during the forward and reverse sweeps of the gate voltage. Various mechanisms are employed to explain the phenomena. ${ }^{35}$ The hysteresis of OTFTs is frequently attributed to the traps at the interface and in the bulk of dielectric. As shown in Fig. 5, the OTFT with $\mathrm{Nb}$ oxide shows a clear anticlockwise hysteresis with a very large $\Delta \mathrm{V}_{\mathrm{T}}$. When the La content is increased to $64.8 \%$, the hysteresis of the OTFT is reduced greatly to a negligible value of $-0.13 \mathrm{~V}$ and has an opposite direction. Furthermore, the OTFT with La oxide shows a larger clockwise hysteresis.

Oxygen vacancies at the interface and in the bulk of the dielectric act as donor-like traps and are positively charged when they are empty, and neutral when filled with electron. $^{36-38}$ The process that the donor-like traps release electrons can be treated as that they trap holes. These donor-like traps (hole traps) capture the holes fast but release them slowly. During the on-to-off sweep, initially at $\mathrm{V}_{\mathrm{G}}=-5 \mathrm{~V}$, many donor-like traps capture holes, and as $\mathrm{V}_{\mathrm{G}}$ decreases, the trapped holes are slowly released, hence compared with the off-to-on sweep, fewer mobile holes in the channel at a given $\mathrm{V}_{\mathrm{G}}$ (see the inset graphs of Fig. 5(a)), resulting in smaller $\mathrm{I}_{\mathrm{D}}$. In addition, the trapped holes can generate a
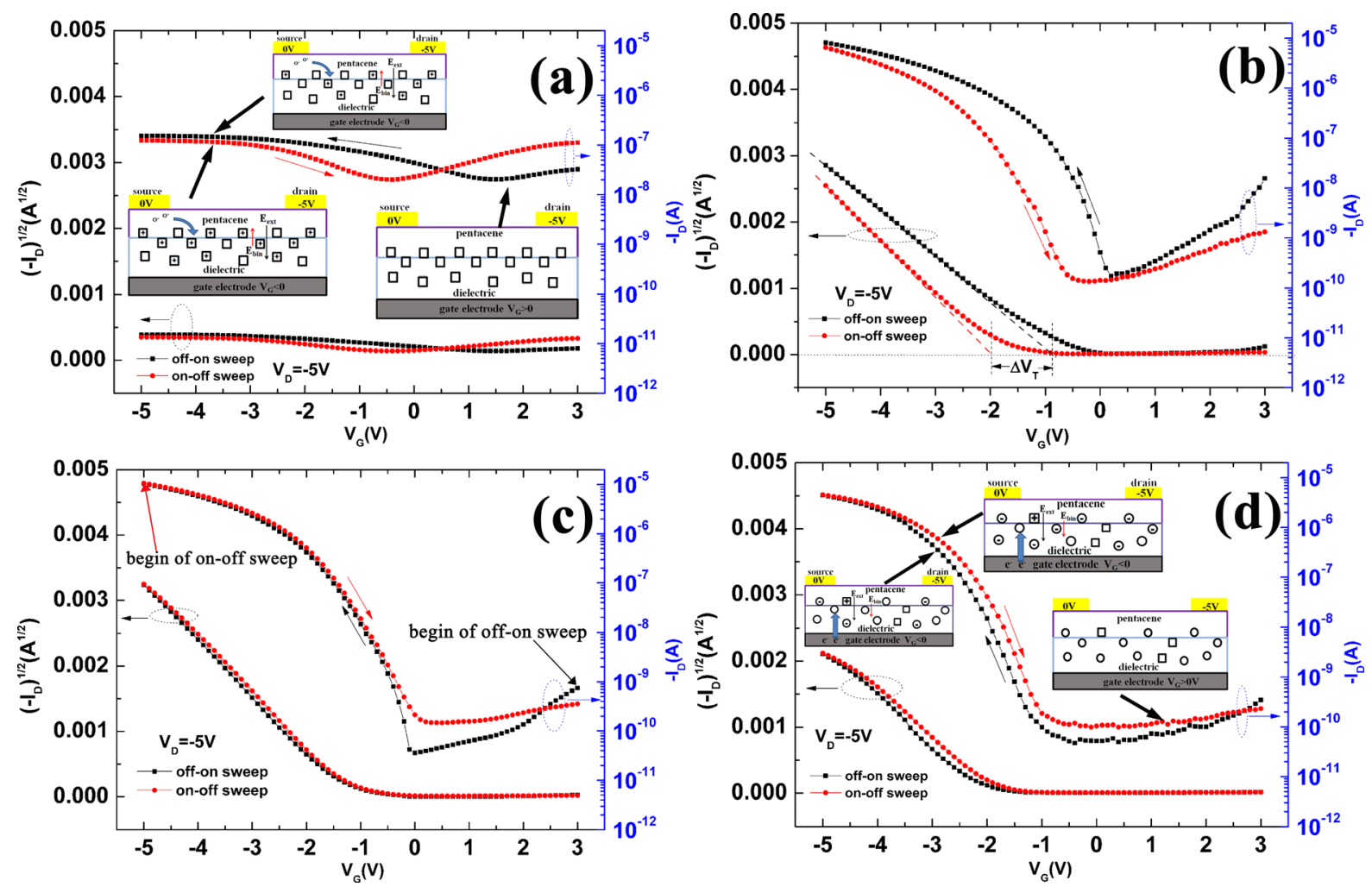

FIG. 5. Transfer and hysteresis characteristics of the OTFTs with different La contents: (a) sample A, (b) sample B, (c) sample C, and (d) sample D; $\square$ and $\boxplus$ represent the filled and empty donor-like traps, respectively; $\bigcirc$ and $\ominus$ are the empty and filled acceptor-like traps, respectively; $\mathrm{O}^{+}$and $\mathrm{e}^{-}$are hole and electron, respectively. 
built-in electric field to oppose the external electric field, and thus, the threshold voltage is shifted to a negative direction, causing an anticlockwise hysteresis as shown in Figs. 5(a) and 5(b). On the other hand, $\mathrm{La}_{2} \mathrm{O}_{3}$ absorbs water and generates hydroxide $(\mathrm{OH})$, which is frequently reported to capture electrons and thus can function as acceptor-like traps in dielectrics. ${ }^{39,40}$ During the on-to-off sweep, electrons are injected from the gate electrode into the dielectric and trapped by the accepter-like traps at the interface and bulk of the dielectric. Upon sweeping $\mathrm{V}_{\mathrm{G}}$ in the positive direction, the electrons remain in the channel and the bulk, generating a built-in electric field to enhance the external electric field, thus accumulating more holes in the channel, leading to larger $I_{D}$ and a shift of the threshold voltage in the positive direction. The clockwise hysteresis is clearly observed in samples C and D (see Figs. 5(c) and 5(d)). Among the samples, sample $\mathrm{C}$ shows the smallest hysteresis. With La incorporation in $\mathrm{Nb}$ oxide, the hysteresis and thus the instability of threshold voltage can be suppressed. In short, the donorlike traps (originated from the oxygen vacancies induced by the $\mathrm{Nb}$ incorporation) cause the anticlockwise hysteresis of the OTFTs, but the acceptor-like traps (due to $\mathrm{OH}$ in $\mathrm{La}_{2} \mathrm{O}_{3}$ after absorbing moisture) produce the opposite hysteresis.

In conclusion, pentacene OTFTs using $\mathrm{La}_{\mathrm{x}} \mathrm{Nb}_{(1-\mathrm{x})} \mathrm{O}_{\mathrm{y}}$ as gate dielectric with different La contents $(x=0,0.347$, $0.648,1)$ have been fabricated. The dielectric films were deposited using co-sputtering of $\mathrm{Nb}$ and $\mathrm{La}_{2} \mathrm{O}_{3}$ targets by varying the sputtering powers of the targets in an $\mathrm{Ar} / \mathrm{O}_{2}$ ambient. The binding-energy shift of the XPS spectrum demonstrates that the La incorporation can suppress the oxygen vacancies in $\mathrm{Nb}$ oxide, thus reducing the nucleation sites at the oxide surface to obtain larger pentacene grains grown. On the other hand, the $\mathrm{Nb}$ incorporation in La oxide can reduce the hygroscopicity of La oxide, resulting in a smoother dielectric surface, which can also give rise to larger pentacene grains. Therefore, with appropriate La content, the OTFT with $\mathrm{La}_{0.764} \mathrm{Ta}_{0.236} \mathrm{O}_{\mathrm{y}}$ as gate dielectric can achieve the largest pentacene grains as well as smoother dielectric surface, and thus the highest carrier mobility of $1.14 \mathrm{~cm}^{2} \mathrm{~V}^{-1} \mathrm{~s}^{-1}$, which is about 1000 times and 2 times those of the devices using $\mathrm{Nb}$ oxide and La oxide, respectively. In addition, the anticlockwise hysteresis of the OTFT with $\mathrm{Nb}_{2} \mathrm{O}_{5}$ is induced by the donor-like traps originated from oxygen vacancies, while the clockwise hysteresis of the OTFT with $\mathrm{La}_{2} \mathrm{O}_{3}$ is caused by the hydroxyl ions in the dielectric after moisture absorption. In summary, $\mathrm{La}$ incorporation in $\mathrm{Nb}$ oxide can passivate its oxygen vacancies, thus obtaining high carrier mobility, small threshold voltage, and negligible hysteresis for the OTFT.

This work was supported by the CRCG Grant of HKU (No. 201409176206), the URC for Seed Fund for Strategic Research Theme of HKU on New Materials, and the University Development Fund (Nanotechnology Research Institute, 00600009) of the University of Hong Kong. The authors would like to thank Dickey Ma for his help.
${ }^{1}$ P. F. Baude, D. A. Ender, M. A. Haase, T. W. Kelley, D. V. Muyres, and S. D. Theiss, Appl. Phys. Lett. 82, 3964 (2003).

${ }^{2}$ M. H. Zhang, S. P. Tiwari, and B. Kippelen, Org. Electron. 10, 1133 (2009).

${ }^{3}$ M. Devynck, P. Tardy, G. Wantz, Y. Nicolas, L. Vellutini, C. Labrugere, and L. Hirsch, Appl. Phys. Lett. 100, 053308 (2012).

${ }^{4}$ J. Roh, C. M. Kang, J. Kwak, C. Lee, and B. J. Jung, Appl. Phys. Lett. 104, 173301 (2014).

${ }^{5}$ W. Wang, J. H. Han, J. Ying, and W. F. Xie, IEEE Trans. Electron Devices 61, 3507 (2014).

${ }^{6}$ H. S. Byun, Y. M. Xu, and C. K. Song, Thin Solid Films 493, 278 (2005).

${ }^{7}$ C. Wang, W.-Y. Lee, R. Nakajima, J. Mei, D. H. Kim, and Z. Bao, Chem. Mater. 25, 4806 (2013).

${ }^{8}$ M. E. Roberts, N. Queralto, S. C. B. Mannsfeld, B. N. Reinecke, W. Knoll, and Z. N. Bao, Chem. Mater. 21, 2292 (2009).

${ }^{9}$ P. Cosseddu, S. Lai, M. Barbaro, and A. Bonfiglio, Appl. Phys. Lett. 100, 093305 (2012).

${ }^{10}$ J. M. Choi, D. K. Hwang, S. H. Jeong, J. H. Park, E. Kim, J. H. Kim, and S. Ima, J. Electrochem. Soc. 154, H331 (2007).

${ }^{11}$ M. Shtein, J. Mapel, J. B. Benziger, and S. R. Forrest, Appl. Phys. Lett. 81, 268 (2002).

${ }^{12}$ R. E. I. Schropp, B. Stannowski, and J. K. Rath, J. Non-Cryst. Solids 299, 1304 (2002).

${ }^{13}$ R. P. Ortiz, A. Facchetti, and T. J. Marks, Chem. Rev. 110, 205 (2010).

${ }^{14}$ N. Umezawa, K. Shiraishi, S. Sugino, A. Tachibana, K. Ohmori, K. Kakushima, H. Iwai, T. Chikyow, T. Ohno, Y. Nara, and K. Yamada, Appl. Phys. Lett. 91, 132904 (2007).

${ }^{15}$ D. Liu and J. Robertson, Appl. Phys. Lett. 94, 042904 (2009).

${ }^{16}$ M. F. Chang, P. T. Lee, S. P. McAlister, and A. S. Chin, IEEE Electron Device Lett. 30, 133 (2009).

${ }^{17}$ C. Y. Han, W. M. Tang, C. H. Leung, C. M. Che, and P. T. Lai, IEEE Electron Device Lett. 34, 1397 (2013).

${ }^{18}$ W. K. Chen, J. Chem. Phys. 47, 1144 (1967).

${ }^{19}$ Y. Zhao, M. Toyama, K. Kita, K. Kyuno, and A. Toriumi, Appl. Phys. Lett. 88, 072904 (2006).

${ }^{20}$ T. L. Duan, H. Y. Yu, L. Wu, Z. R. Wang, Y. L. Foo, and J. S. Pan, Appl. Phys. Lett. 99, 012902 (2011).

${ }^{21}$ S. Guha and V. Narayanan, Phys. Rev. Lett. 98, 196101 (2007).

${ }^{22}$ K. Xiong, J. Robertson, M. C. Gibson, and S. J. Clark, Appl. Phys. Lett. 87, 183505 (2005).

${ }^{23}$ P. S. Bagus, F. Illas, G. Pacchioni, and F. Parmigiani, J. Electron. Spectrosc. Relat. Phenom. 100, 215 (1999).

${ }^{24}$ S. Steudel, S. De Vusser, S. De Jonge, D. Janssen, S. Verlaak, J. Genoe, and P. Heremans, Appl. Phys. Lett. 85, 4400 (2004).

${ }^{25}$ S. E. Fritz, T. W. Kelley, and C. D. Frisbie, J. Phys. Chem. B 109, 10574 (2005).

${ }^{26}$ D. K. Owens and R. C. Wendt, J. Appl. Polym. Sci. 13, 1741 (1969).

${ }^{27}$ S. Y. Yang, K. Shin, and C. E. Park, Adv. Funct. Mater. 15, 1806 (2005).

${ }^{28}$ P. R. Ribič, V. Kalihari, C. D. Frisbie, and G. Bratina, Phys. Rev. B 80, 115307 (2009).

${ }^{29}$ B. J. Song, K. Hong, W. K. Kim, K. Kim, S. Kim, and J. L. Lee, J. Phys. Chem. B 114, 14854 (2010).

${ }^{30}$ M. Voigt, J. Pflaum, and M. Sokolowski, Phys. Status Solidi A 205, 449 (2008).

${ }^{31}$ M. C. Kwan, K. H. Cheng, P. T. Lai, and C. M. Che, Solid State Electron. 51, 77 (2007).

${ }^{32}$ S. Godlewski and M. Szymonski, Int. J. Mol. Sci. 14, 2946 (2013).

${ }^{33}$ C. Sanchez-Sanchez, G. Bavdek, D. Cvetko, M. F. Lopez, J. A. MartinGago, and L. Floreano, J. Phys. Chem. C 115, 4664 (2011).

${ }^{34}$ W. L. Kalb and B. Batlogg, Phys. Rev. B 81, 035327 (2010).

${ }^{35}$ M. Egginger, S. Bauer, R. Schwödiauer, H. Neugebauer, and N. S. Sariciftci, Monatsh Chem. 140, 735 (2009).

${ }^{36}$ R. F. Janninck and D. H. Whitmore, J. Chem. Phys. 37, 2750 (1962).

${ }^{37}$ H. Sawada and K. Kawakami, J. Appl. Phys. 86, 956 (1999).

${ }^{38}$ H. B. Xiao, C. P. Yang, C. Huang, L. F. Xu, D. W. Shi, V. V. Marchenkov, I. V. Medvedeva, and K. Baürner, J. Appl. Phys. 111, 063713 (2012).

${ }^{39}$ L. L. Chua, J. Zaumseil, J. F. Chang, E. C. W. Ou, P. K. H. Ho, H. Sirringhaus, and R. H. Friend, Nature 434, 194 (2005).

${ }^{40}$ S. H. Kim, H. Yang, S. Y. Yang, K. Hong, D. Choi, C. Yang, D. S. Chung, and C. E. Park, Org. Electron. 9, 673 (2008). 